\title{
Generalized Tonic-clonic Seizures Following Spinal Anesthesia Using Bupivacaine for Cesarean Section: A Case Report
}

\author{
Jasleen Kaur ${ }^{1}$, Sukhman K Gill ${ }^{2}$, Anita Kumari ${ }^{3}$, Chiteshwar Walia ${ }^{4}$, Harmandeep Kaur ${ }^{5}$
}

\begin{abstract}
Background: Generalized seizures have been reported following epidural anesthesia but rarely after spinal anesthesia.

Aim and objective: The aim and objective of our study is to create awareness about a rare possibility of bupivacaine-induced generalized tonic-clonic seizures.

Case description: A 19-year-old primigravida with no history of any medical disease had episodes of generalized tonic-clonic seizures following spinal anesthesia. The patient lost consciousness and was immediately intubated after two episodes of seizures. Later on, she was shifted to the intensive care unit for mechanical ventilation.

Conclusion: Although convulsions following spinal anesthesia are rare, parturients can develop complications such as generalized tonicclonic seizures, respiratory depression, and loss of consciousness following spinal anesthesia. These patients require stringent and meticulous monitoring in perioperative period as those for general anesthesia.

Keywords: Bupivacaine, Cesarean section, Spinal anesthesia, Tonic-clonic seizures.

AMEI's Current Trends in Diagnosis \& Treatment (2020): 10.5005/jp-journals-10055-0081
\end{abstract}

\section{INTRODUCTION}

Spinal anesthesia for cesarean section has many advantages over general anesthesia such as it avoids airway manipulation, lessens the risk of gastric aspiration, avoids use of anesthetic agents, have less neonatal depression, and maintains airway reflexes and consciousness. ${ }^{1}$ There are several complications related to spinal anesthesia in cesarean section such as postdural puncture headache (PDPH), back pain, abscess, hematoma, paresthesia, motor weakness, and rarely myoclonus. ${ }^{2,3}$ But generalized tonicclonic seizures (GTCS) are rarely reported. Bupivacaine is the most commonly used local anesthetic in spinal anesthesia during cesarean section, and it has more central nervous system and cardiovascular system side effects than newly discovered local anesthetics such as levobupivacaine and ropivacaine. ${ }^{4}$ Here, we report a rare case of primi parturient who developed GTCS following spinal anesthesia using bupivacaine.

\section{Case Description}

A 19-year-old primigravida with period of gestation of $39+5$ weeks was suggested for emergency cesarean section with indication of meconium-stained liquor. Preoperative investigations and electrocardiography were within normal limits, with hemoglobin $12.4 \mathrm{~g} \%$, TLC count of 10,400 , and PTI $93.3 \%$. Her trimester history was uneventful. She was premedicated with inj. ranitidine and inj. metoclopramide. On arrival to the operating room, monitors were attached. She had stable vitals with heart rate $(\mathrm{HR})$ of 92 beats per minute (bpm), blood pressure (BP) was $124 / 76 \mathrm{~mm} \mathrm{Hg}$ in left arm supine, and saturation $\left(\mathrm{SpO}_{2}\right)$ was $99 \%$ on room air. Intravenous (I/V) line was secured, and the patient was preloaded with $500 \mathrm{~mL}$ of ringer lactate. Under all aseptic precautions, spinal anesthesia was given in left lateral decubitus position using 25-Gauge Quincke' needle in L3 to L4 intervertebral space using midline approach;
${ }^{1-5}$ Department of Anesthesia, Sri Guru Ram Das Institute of Medical Sciences and Research, Amritsar, Punjab, India

Corresponding Author: Sukhman K Gill, Department of Anesthesia, Sri Guru Ram Das Institute of Medical Sciences and Research, Amritsar, Punjab, India, Phone: +91 6239705523, e-mail: sukhugill6666@gmail. com

How to cite this article: Kaur J, Gill SK, Kumari A, et al. Generalized Tonic-clonic Seizures Following Spinal Anesthesia Using Bupivacaine for Cesarean Section: A Case Report. AMEl's Curr Trends Diagn Treat 2020;4(1):29-30.

Source of support: Nil

Conflict of interest: None

$2.2 \mathrm{~mL}$ of $0.5 \%$ heavy bupivacaine was administered after checking free flow of cerebrospinal fluid (CSF). Patient was made supine immediately, and vitals were checked. After checking adequate effect, surgery was allowed to commence. A healthy female baby was delivered. On table at the time of closure, patient started complaining of headache and neck rigidity. She had an episode of GTCS and became unconscious after two such episodes. At the time of GTCS, her HR was 102 bpm, BP was $134 / 74 \mathrm{~mm} \mathrm{Hg}$, and $\mathrm{SpO}_{2}$ was $95 \%$ on oxygen mask. An oral airway was kept in situ, and the patient was immediately taken on bag and mask ventilation with $100 \%$ oxygen. Propofol $70 \mathrm{mg}$ was given to facilitate intubation. After intubation she was shifted to intensive care unit (ICU) for mechanical ventilation and further management.

The patient had two more episodes of GTCS in next 6 hours on ventilator and was kept sedated with an infusion of midazolam and butorphanol. A provisional diagnosis of either bacterial or viral or aseptic meningitis was made, so I/V prophylactic antibiotics were administered. Levetiracetam $500 \mathrm{mg} \mathrm{I/V} 12$ hourly and 

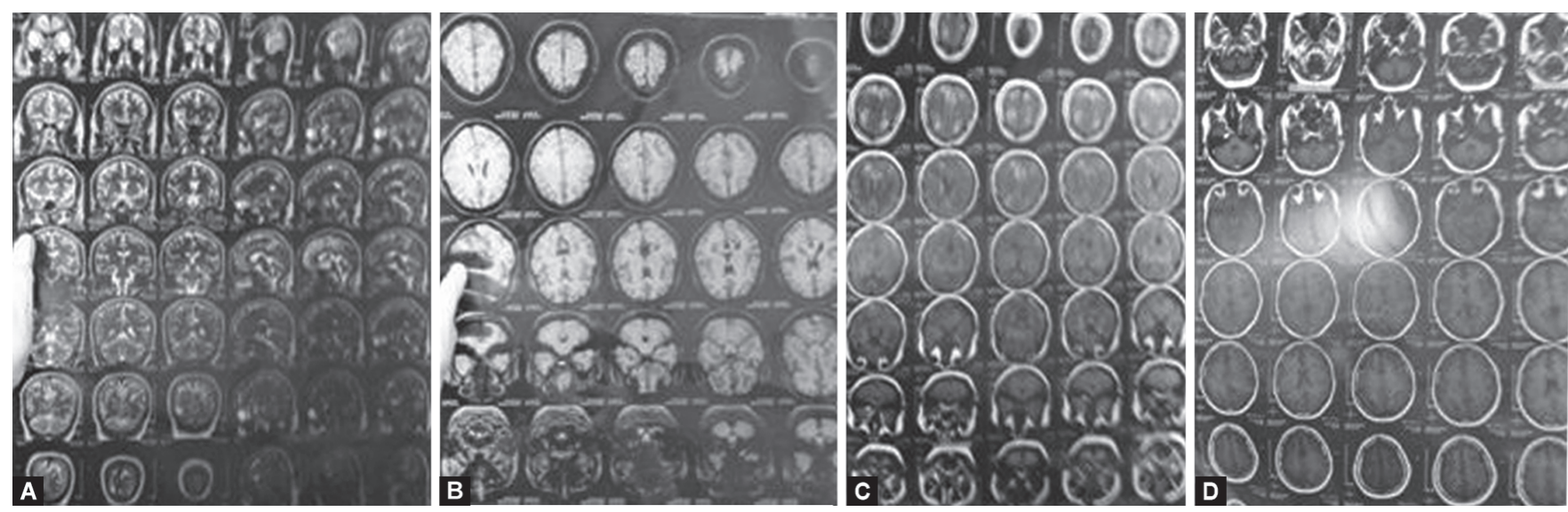

Figs $1 \mathrm{~A}$ to $\mathrm{D}$ : Magnetic resonance imaging of the brain showing leptomeningitis

sodium valproate in a dose of $10 \mathrm{mg} / \mathrm{kg} /$ day I/V were added to control seizures. Magnetic resonance imaging was done which revealed bulky and edematous sulcogyral folds with abnormal areas of signal intensity along the leptomeninges-likely to be leptomeningitis with associated evolving cerebritis (possibility of chemical meningitis) (Fig. 1). CSF tap examination was done and was within normal limits with TLC count of 12 (nine neutrophils and three lymphocytes), protein 103, glucose 76, and ADA 16. Routine blood investigations, electrolytes, and blood gas analysis were also normal throughout her stay in the ICU. Based on investigations and clinical condition, diagnosis of aseptic meningitis was made, and she was kept on supportive treatment along with empirical antibiotics and antiepileptics. After 2 days, sedation was tapered off and the patient became conscious. Ventilatory support was weaned off according to her clinical condition and was then extubated. Patient was shifted to general ward after an uneventful recovery and got discharged on the fifth postoperative day. At 3 months follow-up, the patient had no complaint of any neurological deficit or any similar episodes of seizures.

\section{Discussion}

Several neurological complications associated with spinal anesthesia are reported in the literature such as meningitis, arachnoiditis, neurological injury, PDPH, paresthesias, and myoclonus, but, GTCS is rarely reported..$^{5-7}$

Kim et al. in 2011 reported a similar case report of a parturient posted for cesarean section which was being conducted under spinal anesthesia, who had GTCS 3 minutes after the delivery of baby. She was intubated under the cover of propofol and succinylcholine and oxygenated on manual bag and mask ventilation. After 30 minutes, spontaneous respiration returned. After checking for responsiveness and vitals, on-table extubation was done. Her postoperative period was uneventful. So they concluded that preoperative emotional stabilization with intraoperative critical monitoring of consciousness and respiration should be done during spinal anesthesia. ${ }^{7}$

Similarly, in 2014, Akıl et al. reported a case of 23-year-old male posted for varicocele repair who had an episode of pain in perineal region followed by myoclonic movement 15 minutes after intrathecal administration of $12.5 \mathrm{mg}$ bupivacaine; $15 \mathrm{~mL}$ of $1 \%$ prilocaine was administered locally that relieved pain in perineal region, but just before the completion of surgery, the patient developed GTCS for 3 minutes which was treated with $10 \mathrm{mg} \mathrm{I/V}$ diazepam. He again developed seizures after 8 minutes, so he was administered $10 \mathrm{mg}$ diazepam and $20 \mathrm{mg} / \mathrm{kg}$ of valproate followed by $3 \mathrm{mg} / \mathrm{kg}$ of valproate infusion for 10 minutes. But when seizures did not recede, the patient was intubated after giving $1 \mathrm{mg} / \mathrm{kg}$ of propofol followed by infusion at rate of $1 \mathrm{mg} / \mathrm{kg} / \mathrm{hour}$. Patient was stabilized and extubated after tapering propofol. They concluded that intrathecal bupivacaine may lead to status epilepticus. ${ }^{8}$

\section{Conclusion}

Convulsions following spinal anesthesia are rare. Parturients can develop complications such as GTCS, respiratory depression, and loss of consciousness following spinal anesthesia. So these patients require stringent and meticulous monitoring in the perioperative period. Treatment of seizures involves managing convulsions, rectifying the respiratory depression, and metabolic acidosis in such case is of utmost importance.

\section{References}

1. Bucklin BA, Hawkins JL, Anderson JR, et al. Obstetric anesthesia workforce survey: twenty-year update. Anesthesiol 2005;103(3): 645-653. DOI: 10.1097/00000542-200509000-00030.

2. Finucane B. Complications of Regional Anesthesia. 2nd ed., Springfield (IL): Springer; 2007. p. 140.

3. Menezes FV, Venkat N. Spinal myoclonus following combined spinalepidural anaesthesia for caesarean section. Anaesth 2006;61(6): 597-600. DOI: 10.1111/j.1365-2044.2006.04655.x.

4. Akerman B, Hellberg IB, Trossvik C. Primary evaluation of the local anesthetic properties of the amino amide agent ropivacaine (LEA 103). Acta Anesthes Scand 1988;32(7):571-578. DOI: 10.1111/j.13996576.1988.tb02788.x.

5. Ducornet A, Brousous F, Jacob C, et al. Meningitis after spinal anaesthesia: think about bupivacaine. Ann Fr Anesth Reanim 2014;33(4):288-290. DOI: 10.1016/j.annfar.2014.02.019.

6. Doğan R, Horasanli B, özçimen EE, et al. A case of postpartum seizures following spinal anesthesia and epidural blood pach. Gynecol Obstet Reprod Med 2011;17:110-112.

7. Kim HJ, Kwon MY, Kang HJ, et al. Generalized tonic-clonic seizure following spinal anesthesia for cesarean section with bupivacaine - a case report. Anesth Pain Med 2011;6:393-396.

8. Akıl E, Varol S, Güzel A, et al. Status epilepticus induced by intrathecal bupivacaine use: a case report. J Clin Exp Invest 2014;5(1):108-111. DOI: 10.5799/ahinjs.01.2014.01.0371. 